\title{
Associations among Outdoor Playtime, Screen Time, and Environmental Factors in Japanese Preschoolers: The 'Eat, Be Active, and Sleep Well' Study
}

\author{
Qiang Wang ${ }^{1}$, Jiameng Ma ${ }^{2}$, Kenji Harada ${ }^{2}$, Shiho Kobayashi ${ }^{3}$, Hiroko Sano ${ }^{4}$ and Hyunshik Kim ${ }^{2, *}$ (i) \\ 1 College of Sports Science, Shenyang Normal University, Shenyang 110034, China; 13804999441@163.com \\ 2 Faculty of Physical Education, Sendai University, Shibata-machi 9891693, Japan; jm-ma@sendai-u.ac.jp (J.M.); \\ kn-harada@sendai-u.ac.jp (K.H.) \\ 3 Faculty of Preschool Education, Osaka Seikei College, Osaka 5330007, Japan; \\ kobayashi-sh@g.osaka-seikei.ac.jp \\ 4 Faculty of Humans Sciences, Sendai Shirayuri Women's College, Sendai 9813107, Japan; \\ h-sano@sendai-shirayuri.ac.jp \\ * Correspondence: hs-kim@sendai-u.ac.jp; Tel.: +81-224-55-1592
}

\section{check for}

updates

Citation: Wang, Q.; Ma, J.; Harada, K.; Kobayashi, S.; Sano, H.; Kim, H.

Associations among Outdoor

Playtime, Screen Time, and

Environmental Factors in Japanese

Preschoolers: The 'Eat, Be Active, and Sleep Well' Study. Sustainability 2021,

13, 12499. https://doi.org/

$10.3390 /$ su132212499

Academic Editors: Catharine Ward Thompson and Francisca Lima

Received: 22 September 2021

Accepted: 8 November 2021

Published: 12 November 2021

Publisher's Note: MDPI stays neutral with regard to jurisdictional claims in published maps and institutional affiliations.

Copyright: (c) 2021 by the authors. Licensee MDPI, Basel, Switzerland. This article is an open access article distributed under the terms and conditions of the Creative Commons Attribution (CC BY) license (https:/ / creativecommons.org/licenses/by/ $4.0 /)$.
Abstract: This cross-sectional study investigated regional differences in outdoor playtime and screen time among preschool-age children in Japan, and their associations with environmental factors, in order to identify the modifiable determinants of the differences between urban and rural areas. Data were obtained from the "Eat, be active, and sleep well" study. Children from three $(n=872)$ and five $(n=744)$ kindergartens in urban and rural regions of Japan, respectively, who completed a questionnaire survey, were sampled. Finally, data from 1128 participants (age: 3-5 years) were analyzed. To assess the environmental factors, the International Physical Activity Questionnaire was used for neighborhood environments; the Global Physical Activity Questionnaire was used for physical home environments; and a three-item questionnaire was used for sociocultural environments. Outdoor activity was significantly associated with items related to the mother's sedentary time and the number of siblings/friends in both urban and rural regions. Screen time was associated with the mother's screen time, television in the room, and esthetic qualities, which were consistent between urban and rural regions, while screen time was associated with night-time crime rates and traffic in the urban region. Our study further bolsters evidence suggesting that outdoor playtime and screen time are strongly associated with various environmental factors among Japanese preschool-age children.

Keywords: outdoor play; screen time; preschool-age children; environment; urban/rural

\section{Introduction}

Physical activity (PA) habits established in early childhood are reported to have a notable impact on the healthy growth and development of children [1]. However, in recent years, many children do not have adequate levels of healthy PA, as shown by their reduced outdoor playtime and increased screen time. The 24-h Movement Guidelines, published by the World Health Organization (WHO) [2], indicate that substituting indoor playtime with outdoor playtime would enable children to achieve more moderate-to-vigorous PA (MVPA) and health benefits [3]. Previous studies have shown that preschool-age children achieve more MVPA in outdoor play than in indoor play [4,5], and on the basis of these results, some studies have reported that simply increasing the outdoor playtime of preschoolage children can boost their daily PA level [6,7]. Outdoor play refers to unorganized PA performed outdoors [8]. Periodic and adequate outdoor play is a key approach for PA in children [9], and an important factor that promotes physical, mental, and social development [10-13]. Nevertheless, time spent on outdoor play has shown a marked decline among children in Western countries, such as the United States, Australia, Canada, and The Netherlands, over the past few decades [14-17]. 
Screen time accounts for the greatest percentage of sedentary behavior (SB) in children, and it includes the time spent watching television (TV), videos (VHS) and DVDs, and playing computer and electronic games [18]. SB begins in early childhood [19]; a previous study reports that preschool-age children (age range: 3-5 years) have $12 \mathrm{~h}$ of sedentary time (objectively measured) a day [20]. In recognition of the SB owing to screen time, the WHO recommends less than one hour of screen time for young children, aged 2-4 years, and prohibiting screen time for infants aged 0-1 year [2]. Owing to increased online classes since the outbreak of the coronavirus disease, SB has become essential for the intellectual development of children. However, excessive sedentary time can lead to adverse health outcomes [21], and high sedentary time, particularly screen time, is perceived as a serious social problem pertaining to children's health [22]. Recently, several Western countries, particularly Canada, have set young children's screen time as a major public health target in light of previous findings that report that screen time patterns established in early childhood persist into adulthood. The screen time adherence rate is markedly low in Japan. Interventions to reduce screen time among preschool-age children in Japan are essential from a public health perspective $[23,24]$.

The ecological model is a useful framework for understanding the various levels of correlations between, and determinants of, health behaviors. Individual behaviors, such as outdoor play and screen time, are assumed to be influenced by multiple factors, such as family, society, organization, and environment [25]. The community and physical environment may serve as more important determinants of PA and screen time in children than in adults. Therefore, low PA and high screen time are currently suggested as factors causing health problems in Japanese children. To change this situation, a review of the related factors, using ecological models in this study, will have importance. Furthermore, interventions for a specific group are needed to improve health behaviors, and the area of residence (urban and rural regions), a determinant of behavior that has gained much attention recently, needs to be investigated through ecological-model-based analyses [9]. Particularly, children's PA and screen time may differ across their living environments. Previous studies have reported inconsistent findings regarding the differences between rural and urban environments in children [26-29]. Moreover, previous studies that have analyzed the relationship among the living environment (urban and rural areas), outdoor activities, and screen time have been conducted, mainly in the West, but very few studies have been conducted on preschool-age children in Japan. Particularly, only a few published studies have analyzed the living environment and ecological factors affecting children. Accordingly, the current study has unique significance.

The present study aimed to investigate regional differences in outdoor playtime and screen time among preschool-age children in Japan, and their associations with environmental factors, in order to identify the modifiable determinants of the differences between urban and rural areas.

\section{Materials and Methods}

\subsection{Study Design and Participants}

This was a cross-sectional study, and data were obtained from the "Eat, be active, and sleep well" study-a project targeting lifestyle improvement in young children in East Asia [30]. On the basis of the definitions of the populations, number of households, occupations, and urban facilities per city, town, and village classifications, as used by the Enforcement Decree of the Local Autonomy Act of Japan, enacted in 1947, Nishinomiya-shi (population: 487,800 persons; surface area: $99.96 \mathrm{~km}^{2}$ ) was selected as the urban region, and Ōhira-mura (population: 5918 persons; surface area: $60.32 \mathrm{~km}^{2}$ ) and Tomiya-shi (population: 52,340 persons; surface area: $49.18 \mathrm{~km}^{2}$ ) were selected as the rural regions. Children from three kindergartens $(n=872)$ in Nishinomiya-shi (urban region), and five kindergartens $(n=744)$ in Ōhira-mura and Tomiya-shi (rural regions), completed a questionnaire, in accordance with the Declaration of Helsinki. We obtained consent from the participating children, aged 3-5 years, their parents, and teachers, and data from 1178 participants who 
signed written consents ( $50.2 \%$ boys, $49.8 \%$ girls; collection rate $=69.8 \%$ ) were analyzed. The study received prior approval from the Sendai University Ethics Committee of the Faculty of Sports Science (approval no.: SU29-22).

\subsection{Measures}

\subsubsection{Environmental Factors}

In order to assess the perceived neighborhood environments, we administered the environmental module of the International Physical Activity Questionnaire (IPAQ-E) [31]. The IPAQ-E consists of 17 items related to the environment. Of the seven key items, four recommended items, and six optional items, we used ten items, including key and recommended items. The IPAQ-E questions included access to shops, public transport, the presence of sidewalks and bicycle lanes, access to exercise facilities, crime safety, traffic safety, the social environment, esthetics, and the number of motor vehicles in the participant's household. These questions refer to a person's neighborhood environment within a 10-15 min walking distance from their residence. The other nine questions were scored using a four-point Likert response scale (strongly disagree, somewhat disagree, somewhat agree, and strongly agree). One question was related to the number of motor vehicles owned by the households. The Japanese version of the IPAQ-E has shown good test-retest reliability [32].

The physical home environment pertains to the family, particularly the mother's, physical environment, in our study (mother's daily sedentary time, screen time, and MVPA). The Global Physical Activity Questionnaire (GPAQ) was developed in 2002 as an internationally standardized questionnaire to investigate PA levels and is widely used in policy development by the WHO [33]. This self-reported questionnaire consists of 16 questions that assess PA in three domains: work, transport, and leisure. We calculated the average daily hours of work-related vigorous PA, work-related moderate PA, transportrelated PA, leisure vigorous PA, leisure moderate PA, and total PA. The validity of the Japanese version of the GPAQ has been confirmed [34].

The "sociocultural environment" aspect is comprised of three items. The items "There is a TV and computer in my child's bedroom" and "I set limit for the place or method of outdoor play as we worry about potential injuries" were structured as yes-or-no questions, and the item "the number of people who accompany outdoor activities, including siblings and friends" was structured as an open-ended question.

\subsubsection{Outdoor Playtime}

The question about the outdoor playtime of preschool-age children was structured as an open-ended question, where parents were asked to specify the daily average outdoor playtime on weekdays and weekends separately. The answer options for outdoor playtime were $0,1-15,16-30,31-60$, and $\geq 61 \mathrm{~min}$. With reference to an outdoor playtime checklist by Burdettes et al. [35], children's outdoor play was assessed by asking parents how much time before noon, from noon until 6:00 p.m., and after 6:00 p.m. the child spent playing in the yard or street around the house and in the park/playground/outdoor recreation area. For an accurate assessment of the daily average outdoor playtime on weekdays, the outdoor playtime in kindergarten was additionally surveyed by asking kindergarten teachers, and a duration of $60 \mathrm{~min}$ per day was set as the reference outdoor playtime.

\subsubsection{Screen Time}

Screen time was assessed by asking parents how much time their children spent watching TV and using smartphones, tablets, and computers in the past week, using the following questions: (1) How many media devices, including TVs, smartphones, tablets, and computers, are available at home? (2) How much time does your child spend watching TV or videos in a day? and (3) For how long, on average, does your child use electronic devices, such as smartphones, tablets, and computers, in a day? Subsequently, parents were asked to indicate the average number of days per week and weekends that their 
child spent on screen viewing, based on the following six options: $0,1-29,30-59,60-119$, $120-179$, or $\geq 180 \mathrm{~min}$. To calculate the average time spent on screen-viewing activities per week or weekend, the number of days per week or weekend the child spent time on activities was multiplied by the mid-category values of the duration of the activity per day. Weekday and weekend values were combined and divided by the total number of days [30].

\subsection{Demographics}

Demographic variables included the child's sex, age, height, and weight and the mother's employment status, height, and weight. Data were obtained from their respective parents.

\subsection{Statistical Analyses}

Data from 1178 young Japanese children (urban: 627; rural: 551) who provided complete information on the study variables were analyzed using two models. The first model was tested using independent $t$-tests to analyze the differences in environments-physical home environments and sociocultural home environments-between the urban and rural areas. The second model was tested using univariate simple linear regression analysis using the enter method to analyze the association between the urban and rural regions with each of the environmental variables. We used univariate multiple linear regression analysis adjusted for sex and age, and all variables included in each of the multivariate models were assessed for multicollinearity, which is prevalent among neighborhood environmental characteristics [36]. All statistical analyses were conducted using SPSS (version 26.0; IBM, Armonk, NY, USA), and the level of significance was set at a $p$-value of $<0.05$.

\section{Results}

\subsection{Study Population}

The characteristics of the children and mothers by region are presented in Table 1. Children in urban regions included a higher percentage of girls and were older than those in rural regions. With regard to the mothers, the obesity rate was higher in the rural region $(23.1 \%)$ than in the urban region $(14.9 \%)(p<0.001)$. With regard to employment status, the percentage of mothers with a full-time job was higher in the rural region $(55.4 \%)$ than in the urban region $(17.7 \%)(p<0.001)$.

Table 1. Sociodemographic characteristics and urban/rural differences among mothers and their children.

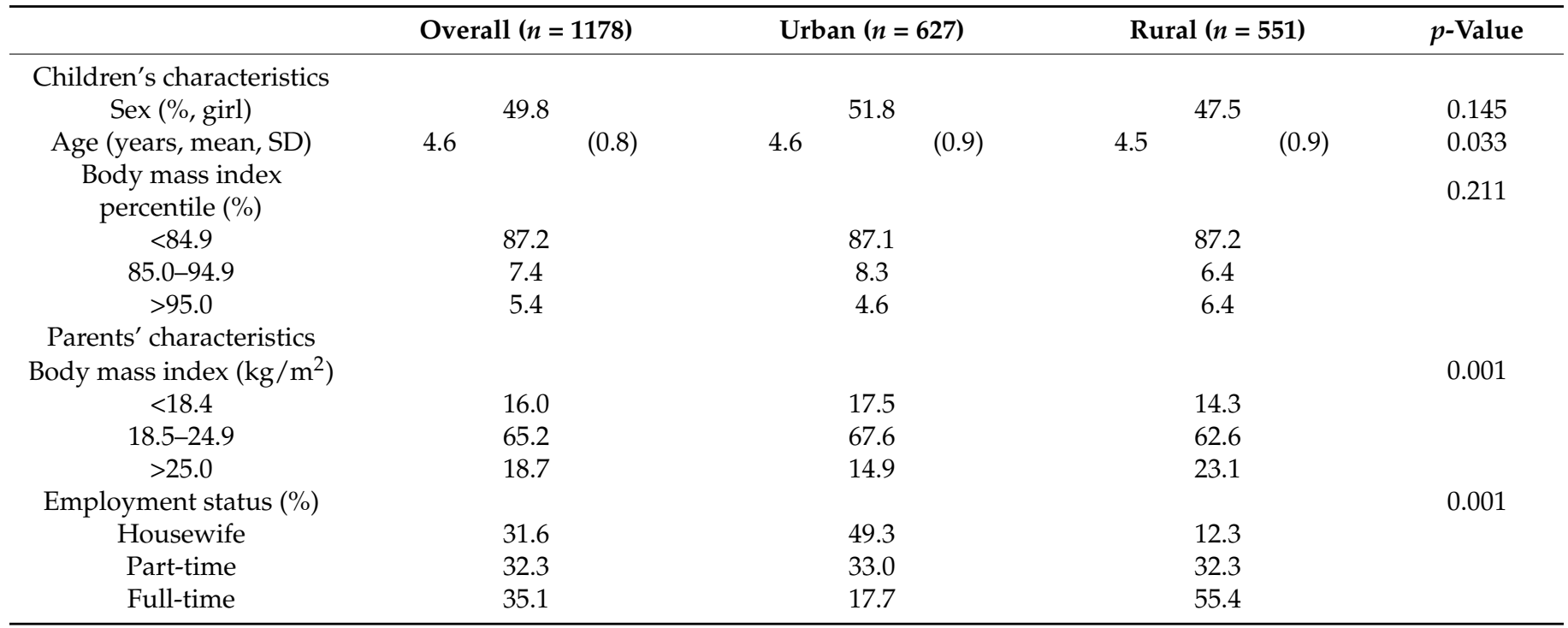

Note: SD, standard deviation. Group differences for continuous variables were assessed using $t$-tests and categorical variables were assessed using chi-squared tests. 
The mean outdoor playtimes and screen times, according to region and daily recommendations, are presented in Table 2. Weekday outdoor playtime was longer among children in urban regions $(p<0.001)$, whereas weekday screen time was longer among children in rural regions $(p<0.001)$. Additionally, the percentage of children complying with the daily screen time recommendation was higher in the urban region $(46.4 \%)$ than in the rural region $(40.7 \%)$, and compliance with the weekend screen time recommendation was higher in the urban region (25.8\%) than in the rural region $(16.5 \%)$.

Table 2. Descriptive and urban/rural differences in children's outdoor playtime, screen time, and compliance with recommendations.

\begin{tabular}{|c|c|c|c|c|}
\hline Variables & Overall $(n=1178)$ & Urban $(n=627)$ & Rural $(n=551)$ & $p$-Value \\
\hline \multicolumn{5}{|c|}{ Outdoor playtime (minute: mean, SD) } \\
\hline Weekdays & $36.6(26.8)$ & $38.8(26.2)$ & $28.9(25.2)$ & 0.001 \\
\hline Weekend & $97.3(58.5)$ & $97.4(60.0)$ & $95.2(57.2)$ & 0.559 \\
\hline \multicolumn{5}{|c|}{ Screen time (minute: mean, SD) } \\
\hline Weekdays & $127.5(82.1)$ & $119.4(73.1)$ & $122.5(80.5)$ & 0.523 \\
\hline Weekend & $185.9(10.9 .9)$ & $167.7(103.9)$ & $195.4(105.0)$ & 0.001 \\
\hline \multicolumn{5}{|c|}{$\begin{array}{l}>60 \mathrm{~min} / \text { day in outdoor playtime, } \\
\text { weekdays }(\%)\end{array}$} \\
\hline Yes & 14.9 & 14.2 & 15.6 & 0.496 \\
\hline No & 85.1 & 85.8 & 84.4 & \\
\hline \multicolumn{5}{|c|}{$\begin{array}{l}>60 \mathrm{~min} / \text { day in outdoor playtime, } \\
\text { weekend }(\%)\end{array}$} \\
\hline Yes & 54.7 & 54.5 & 54.8 & 0.928 \\
\hline No & 45.3 & 45.5 & 45.2 & \\
\hline \multicolumn{5}{|c|}{$\begin{array}{l}<60 \mathrm{~min} / \text { day in screen time, weekdays } \\
(\%)\end{array}$} \\
\hline Yes & 43.7 & 46.4 & 40.7 & 0.047 \\
\hline No & 56.3 & 53.6 & 59.3 & \\
\hline \multicolumn{5}{|c|}{$<60 \mathrm{~min} /$ day in screen time, weekend (\%) } \\
\hline Yes & 21.5 & 25.8 & 16.5 & 0.001 \\
\hline No & 78.5 & 74.2 & 83.5 & \\
\hline
\end{tabular}

Note: SD, standard deviation. Group differences for continuous variables were assessed using $t$-tests and categorical variables were assessed using chi-squared tests.

\subsection{Environment Variables of Urban and Rural Participants}

The environmental variables and differences between urban and rural regions are presented in Table 3. For the "neighborhood environment" domain, the scores were significantly higher in the urban region for all items, except for the items, "crime rates during the night" and "motor vehicles." For the "physical home environment" domain, the scores for all variables were significantly higher in the urban region ("mother's sedentary time", "mother's screen time", and "mother's PA") than in the rural region. For the "sociocultural home environment" domain, the score for "setting a limit to the place or method of outdoor play" was higher in the rural region, whereas the scores for "TV in the room" and "number of siblings/friends" were higher in the urban region. 
Table 3. Mean (SD) of environmental correlates for urban $(n=627)$ and rural $(n=551)$ participants.

\begin{tabular}{|c|c|c|c|}
\hline Environmental Variables & $\begin{array}{c}\text { Urban } \\
\text { Mean (SD) }\end{array}$ & $\begin{array}{c}\text { Rural } \\
\text { Mean (SD) }\end{array}$ & $t$ \\
\hline \multicolumn{4}{|l|}{ Neighborhood environments ${ }^{a}$} \\
\hline $\begin{array}{l}\text { What is the main type of housing in your } \\
\text { neighbourhood? }\end{array}$ & $2.11(1.3)$ & $1.25(0.6)$ & $13.38^{* * *}$ \\
\hline $\begin{array}{l}\text { Many shops, stores, markets, or other places to buy } \\
\text { things I need are within easy walking distance of my } \\
\text { home. }\end{array}$ & $2.98(0.9)$ & $1.98(1.1)$ & $16.26^{* * *}$ \\
\hline $\begin{array}{l}\text { It is within a } 10-\text { to } 15-\text { min walk to a transit stop from } \\
\text { my home. }\end{array}$ & $3.45(0.8)$ & $2.81(1.1)$ & $10.96^{* * *}$ \\
\hline $\begin{array}{l}\text { There are sidewalks on most of the streets in my } \\
\text { neighbourhood. }\end{array}$ & $2.85(1.5)$ & $2.72(0.9)$ & 1.65 \\
\hline $\begin{array}{l}\text { There are facilities to bicycle in or near my } \\
\text { neighborhood shared use paths for cycles and } \\
\text { pedestri-ans. }\end{array}$ & $2.00(1.0)$ & $1.37(0.7)$ & $11.90^{* * *}$ \\
\hline $\begin{array}{l}\text { My neighborhood has several free or low-cost } \\
\text { recreation facilities. }\end{array}$ & $2.83(0.8)$ & $2.42(0.9)$ & $7.72^{* * *}$ \\
\hline $\begin{array}{l}\text { The crime rate in my neighbourhood makes it unsafe to } \\
\text { go on walks at night. }\end{array}$ & $2.16(0.7)$ & $2.27(0.8)$ & $2.53 *$ \\
\hline $\begin{array}{l}\text { There is so much traffic on the streets that it makes it } \\
\text { difficult or unpleasant to walk in my neigh-borhood. }\end{array}$ & $2.43(1.3)$ & $2.39(0.7)$ & 0.62 \\
\hline $\begin{array}{l}\text { I see many people being physically active in my } \\
\text { neighborhood. }\end{array}$ & $2.88(0.7)$ & $2.36(0.9)$ & $10.26^{* * *}$ \\
\hline $\begin{array}{l}\text { There are many interesting things to look at while } \\
\text { walking in my neighbourhood. }\end{array}$ & $2.37(0.8)$ & $2.16(1.1)$ & $4.12^{* * *}$ \\
\hline $\begin{array}{l}\text { How many motor vehicles in working order are there at } \\
\text { your household? } \mathrm{d}\end{array}$ & $1.55(1.1)$ & $2.86(2.0)$ & $13.22^{* * *}$ \\
\hline \multicolumn{4}{|l|}{ Physical home environments $\mathrm{b}$} \\
\hline Mother's daily sedentary time. & $223.31(172.1)$ & $284.27(199.9)$ & $5.56^{* * *}$ \\
\hline Mother's daily screen time. & $229.15(165.1)$ & $255.30(191.9)$ & $2.50 *$ \\
\hline Mother's daily moderate-to-vigorous physical activity. & $34.49(100.4)$ & $35.75(98.6)$ & 0.28 \\
\hline \multicolumn{4}{|l|}{ Social-culture environments ${ }^{c}$} \\
\hline There is a TV or a computer in the child's room. & $1.73(0.4)$ & $1.62(0.4)$ & $3.93^{* * *}$ \\
\hline $\begin{array}{l}\text { I limit the place or method of outdoor play as we worry } \\
\text { about potential injuries. }\end{array}$ & $1.25(0.4)$ & $1.27(0.5)$ & 0.27 \\
\hline $\begin{array}{l}\text { The number of people who accompany outdoor play, } \\
\text { including siblings and friends. } \mathrm{d}\end{array}$ & $2.33(1.1)$ & $2.28(0.9)$ & 0.80 \\
\hline
\end{tabular}

Note: ${ }^{a}$ Response option: strongly disagree (1), somewhat disagree (2), somewhat agree (3), strongly agree (4); ${ }^{b}$ Open-ended response open (GPAQ [34]); ${ }^{\mathrm{c}}$ Response option: yes (1), no (2); ${ }^{\mathrm{d}}$ Open-ended response open. ${ }^{*} p<0.05 ;{ }^{* * *} p<0.001$.

\subsection{Environment Variables Associated with Outdoor Playtime}

Multivariate regression analysis after adjusting for sex, age, and body mass index revealed that outdoor playtime was positively associated with the "closer walking distance to local shops", "recreation facilities", "physically active people" items of the "neighborhood environment" domain among urban participants. Furthermore, outdoor playtime was negatively associated with the "mother's sedentary time" item and was positively associated with the "mother's PA" item in the "physical home environment" domain. In the "sociocultural home environment" domain, outdoor playtime was positively associated with the "number of siblings/friends" and "TV in the room" items (Table 4). In contrast, among rural participants, outdoor playtime was negatively associated with the "access to the transit stop" item and was positively associated with the "motor vehicles" item of the "neighborhood environment" domain. 
Table 4. Results from linear regression analyses of environmental correlates and outdoor play time for urban/rural participants.

\begin{tabular}{|c|c|c|c|c|}
\hline \multirow[b]{2}{*}{ Environmental Variables } & \multicolumn{2}{|c|}{ Urban $(n=627)$} & \multicolumn{2}{|c|}{ Rural $(n=551)$} \\
\hline & $\begin{array}{l}\text { Unadjusted } \\
\beta(95 \% \mathrm{CI})^{\mathrm{a}}\end{array}$ & $\begin{array}{c}\text { Adjusted } \\
\beta(95 \% \mathrm{CI})^{\mathrm{b}}\end{array}$ & $\begin{array}{l}\text { Unadjusted } \\
\beta(95 \% \mathrm{CI})^{\mathrm{a}}\end{array}$ & $\underset{\beta(95 \% \mathrm{CI})^{\mathrm{b}}}{\text { Adjusted }}$ \\
\hline \multicolumn{5}{|l|}{ Neighborhood environments $^{c}$} \\
\hline What is the main type of housing in your neighbourhood? & $-0.042(-3.21,1.00)$ & & $0.032(-3.11,6.88)$ & \multirow{9}{*}{$-0.228(-10.14,-4.62)^{* * *}$} \\
\hline $\begin{array}{l}\text { Many shops, stores, markets, or other places to buy things I need } \\
\text { are within easy walking distance of my home. }\end{array}$ & $0.121(1.57,7.47) * *$ & $0.085(0.14,6.12)^{*}$ & $-0.038(-9.02,2.13)$ & \\
\hline $\begin{array}{l}\text { It is within a } 10 \text { - to } 15 \text {-min walk to a transit stop from my home. } \\
\text { There are sidewalks on most of the streets in my neighbourhood. }\end{array}$ & $\begin{array}{l}0.033(-1.98,4.85) \\
0.068(-0.28,3.49)\end{array}$ & & $\begin{array}{l}-0.239(-10.54,-5.10)^{* * *} \\
-0.015(-5.01,3.41)\end{array}$ & \\
\hline $\begin{array}{l}\text { There are facilities to bicycle in or near my neighborhood shared } \\
\text { use paths for cycles and pedestri-ans. }\end{array}$ & $0.119(1.41,7.04)^{*}$ & & $-0.028(-5.91,3.01)$ & \\
\hline $\begin{array}{c}\text { My neighborhood has several free or low-cost recreation } \\
\text { facilities. }\end{array}$ & $0.168(3.92,10.82)^{* * *}$ & $0.139(2.65,9.51)^{* * *}$ & $-0.076(-6.22,0.36)$ & \\
\hline $\begin{array}{c}\text { The crime rate in my neighbourhood makes it unsafe to go on } \\
\text { walks at night. }\end{array}$ & $0.012(-3.18,4.31)$ & & $0.007(-3.55,4.20)$ & \\
\hline $\begin{array}{l}\text { There is so much traffic on the streets that it makes it difficult or } \\
\text { unpleasant to walk in my neigh-borhood. }\end{array}$ & $-0.055(-6.06,1.11)$ & \multirow{3}{*}{$0.103(1.09,8.17)^{* *}$} & $-0.019(-2.47,1.56)$ & \\
\hline \multirow{2}{*}{$\begin{array}{l}\text { I see many people being physically active in my neighborhood. } \\
\text { There are many interesting things to look at while walking in my } \\
\text { neighbourhood. }\end{array}$} & $0.126(2.13,9.33)^{* *}$ & & $-0.070(-13.52,1.25)$ & \\
\hline & $0.029(-2.08,4.45)$ & & $0.067(-0.75,6.40)$ & \\
\hline $\begin{array}{l}\text { How many motor vehicles in working order are there at your } \\
\text { household? }^{\mathrm{d}}\end{array}$ & $-0.083(-4.97,-0.11)^{*}$ & & $0.091(0.10,3.18)^{*}$ & $0.093(0.15,3.24) *$ \\
\hline \multicolumn{5}{|l|}{ Physical home environments $\mathrm{e}$} \\
\hline $\begin{array}{l}\text { Mother's daily sedentary time. } \\
\text { Mother's dailv screen time. }\end{array}$ & $\begin{array}{l}-0.197(-0.05,-0.02) * * * \\
-0.090(-0.03-0.01) *\end{array}$ & $-0.163(-0.05,-0.01)^{* * *}$ & $\begin{array}{r}-0.164(-0.04,-0.01)^{* * *} \\
0.045(-0.011 .02)\end{array}$ & $\begin{array}{c}-0.167(-0.04,-0.01)^{* * *} \\
0.018(0.01,0.08)^{* *}\end{array}$ \\
\hline \multirow{2}{*}{$\begin{array}{l}\text { There is a TV or a computer in the child's room. } \\
\text { I limit the place or method of outdoor play as we worry about } \\
\text { potential injuries. }\end{array}$} & $0.016(-5.27,7.86)$ & & $-0.094(-13.63,-0.66) *$ & \multirow[t]{2}{*}{$-0.098(-13.94,-0.96) *$} \\
\hline & $-0.016(-7.94,6.35)$ & & $-0.026(-1.83,3.62)$ & \\
\hline $\begin{array}{l}\text { The number of people who accompany outdoor play, including } \\
\text { siblings and friends. }{ }^{d}\end{array}$ & $0.418(10.43,14.81)^{* * *}$ & $0.406(10.03,14.31)^{* * *}$ & $0.288(7.67,13.79)^{* * *}$ & $0.280(7.38,13.52)^{* * *}$ \\
\hline
\end{tabular}

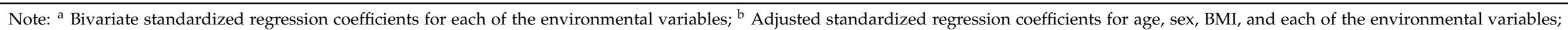

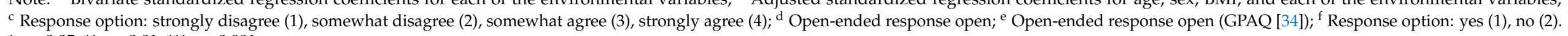

${ }^{*} p<0.05 ;{ }^{* *} p<0.01 ;{ }^{* * *} p<0.001$. 


\subsection{Environment Variables Associated with Screen Time}

The association between screen time and environmental factors was analyzed using the same statistical method as that used for outdoor playtime. Among urban participants, screen time was positively associated with "crime rates during the night", "traffic", "mother's sedentary time", and "mother's screen time", and was significantly negatively associated with "esthetic qualities", "TV in the room", and "number of siblings/friends." Among rural participants, screen time was positively associated with all items ("closer walking distance to local shops", "access to the transit stop", "esthetic qualities", and "TV in the room"), except for the "mother's daily TV and smartphone usage" item (Table 5).

Table 5. Results from linear regression analyses of environmental correlates and screen time for urban/rural participants.

\begin{tabular}{|c|c|c|c|c|}
\hline \multirow[b]{2}{*}{ Environmental Variables } & \multicolumn{2}{|c|}{ Urban $(n=627)$} & \multicolumn{2}{|c|}{ Rural $(n=551)$} \\
\hline & $\begin{array}{l}\text { Unadjusted } \\
\beta(95 \% \mathrm{CI})^{\mathrm{a}}\end{array}$ & $\begin{array}{c}\text { Adjusted } \\
\beta(95 \% \mathrm{CI})^{\mathrm{b}}\end{array}$ & $\begin{array}{l}\text { Unadjusted } \\
\beta(95 \% \mathrm{CI})^{\mathrm{a}}\end{array}$ & $\underset{\beta(95 \% \mathrm{CI})^{\mathrm{b}}}{\stackrel{\text { Adjusted }}{ }}$ \\
\hline \multicolumn{5}{|l|}{ Neighborhood environments ${ }^{c}$} \\
\hline $\begin{array}{c}\text { What is the main type of housing in } \\
\text { your neighbourhood? }\end{array}$ & $-0.048(-9.82,2.40)$ & & $0.073(-1.58,20.79)$ & \\
\hline $\begin{array}{l}\text { Many shops, stores, markets, or other } \\
\text { places to buy things I need are within } \\
\text { easy walking distance of my home. }\end{array}$ & $0.002(-6.48,6.78)$ & & $-0.026(-5.72,3.41)$ & \\
\hline $\begin{array}{l}\text { It is within a } 10-\text { to } 15-\text { min walk to a } \\
\text { transit stop from my home. }\end{array}$ & $-0.022(-9.76,5.48)$ & & $-0.026(-1.48,2.04)$ & \\
\hline $\begin{array}{l}\text { There are sidewalks on most of the } \\
\text { streets in my neighbourhood. }\end{array}$ & $0.015(-5.01,3.41)$ & & $-0.075(-13.58,0.79)$ & \\
\hline $\begin{array}{l}\text { There are facilities to bicycle in or near } \\
\text { my neighborhood shared use paths for } \\
\text { cycles and pedestri-ans. }\end{array}$ & $-0.001(-6.41,6.19)$ & & $-0.007(-5.31,3.71)$ & \\
\hline $\begin{array}{l}\text { My neighborhood has several free or } \\
\text { low-cost recreation facilities. }\end{array}$ & $-0.027(-10.54,5.21)$ & & $-0.070(-13.52,1.24)$ & \\
\hline $\begin{array}{l}\text { The crime rate in my neighbourhood } \\
\text { makes it unsafe to go on walks at night. }\end{array}$ & $0.086(0.65,17.54)^{*}$ & $0.092(1.32,18.12) *$ & $0.027(-5.87,11.38)$ & \\
\hline $\begin{array}{l}\text { There is so much traffic on the streets } \\
\text { that it makes it difficult or unpleasant } \\
\text { to walk in my neigh-borhood. }\end{array}$ & $0.130(5.11,21.22) * * *$ & $0.124(4.54,20.60)^{* *}$ & $0.025(-3.21,5.88)$ & \\
\hline $\begin{array}{l}\text { I see many people being physically } \\
\text { active in my neighborhood. }\end{array}$ & $-0.056(-13.97,2.39)$ & & $-0.056(-12.42,2.57)$ & \\
\hline $\begin{array}{l}\text { There are many interesting things to } \\
\text { look at while walking in my } \\
\text { neighbourhood. }\end{array}$ & $-0.152(-21.38,-6.71) * * *$ & $-0.144(-20.68,-6.06)^{* * *}$ & $-0.135(-20.82,-4.81)^{* * *}$ & $-0.147(-21.87,-5.96) * * *$ \\
\hline $\begin{array}{l}\text { How many motor vehicles in working } \\
\text { order are there at your household? }{ }^{\mathrm{d}} \\
\text { Physical home environments }\end{array}$ & $0.008(-4.95,6.00)$ & & $0.033(-2.13,4.83)$ & \\
\hline Mother's daily sedentary time. & $0.203(0.05,0.13) * * *$ & $0.189(0.05,0.12)^{* * *}$ & $0.065(-0.01,0.06)$ & \\
\hline Mother's daily screen time. & $0.457(0.18,0.25)^{* * *}$ & $0.453(0.19,0.25)^{* * *}$ & $0.259(0.07,0.14)^{* * *}$ & $0.246(0.07,0.14)^{* * *}$ \\
\hline $\begin{array}{l}\text { Mother's daily moderate-to-vigorous } \\
\text { physical activity. } \\
\text { Social-culture environments }\end{array}$ & $-0.040(-0.09,0.03)$ & & $-0.014(-0.08,0.06)$ & \\
\hline $\begin{array}{l}\text { There is a TV or a computer in the } \\
\text { child's room. }\end{array}$ & $-0.151(-41.74,-13.16)^{* * *}$ & $-0.151(-41.50,-13.06)^{* * *}$ & $-0.150(-40.50,-11.52) * * *$ & $-0.151(-40.63,-11.79)^{* * *}$ \\
\hline $\begin{array}{c}\text { I limit the place or method of outdoor } \\
\text { play as we worry about potential } \\
\text { injuries. }\end{array}$ & $0.019(-6.24,5.15)$ & & $-0.029(-1.53,2.82)$ & \\
\hline $\begin{array}{c}\text { The number of people who accompany } \\
\text { outdoor play, including siblings and } \\
\text { friends. }{ }^{d}\end{array}$ & $-0.089(-11.47,0.65) *$ & $-0.088(-11.32,-0.57) *$ & $0.038(-3.92,10.46)$ & \\
\hline
\end{tabular}

Note: ${ }^{a}$ Bivariate standardized regression coefficients for each of the environmental variables; ${ }^{\mathrm{b}}$ Adjusted standardized regression coefficients for age, sex, BMI, and each of the environmental variables; ${ }^{\mathrm{c}}$ Response option: strongly disagree (1), somewhat disagree (2), somewhat agree (3), strongly agree (4); ${ }^{\mathrm{d}}$ Open-ended response open; ${ }^{\mathrm{e}}$ Open-ended response open (GPAQ [34]); ${ }^{\mathrm{f}}$ Response option: yes (1), no (2). ${ }^{*} p<0.05 ;{ }^{* *} p<0.01 ; * * * 0<0.001$.

\section{Discussion}

The present study is one of the first Japanese studies to analyze the ecological factors that affect the outdoor activities and screen time of Japanese preschoolers by region (urban and rural regions). Our results show that outdoor activity was significantly associated with the "mother's sedentary time" and "number of siblings/friends" items in both urban and rural regions. This finding is consistent with the previous findings of Western studies and strongly supports the association of preschool-age children's PA and parents' sedentary time [37], particularly the mother's sedentary time [38]. Additionally, our findings regarding the "number of siblings and friends" support the findings of previous studies that 
found that outdoor playtime increases when friends or families (siblings) are involved [39]. That is, children who live close to friends or family engage in more outdoor play because they are more likely to play with friends or family outdoors than children who do not live close to friends or family [40]. A Taiwanese study reported that children who live in rural regions engage in little PA after school, and on holidays and weekends, which supports our results that outdoor play time is significantly correlated with facilities for outdoor play, PA, and accessibility to places of outdoor play [41]. Previous findings suggest that children who live in urban regions engage in more outdoor play and PA owing to environmental factors that provide them with easier access to community sports programs or sports facilities [42]. Considering several findings that have reported that children's behaviors are associated with neighborhood environments in several Western countries, and that causality exists between outdoor play and health in preschool-age children, these results serve as important evidence, highlighting the need for effective intervention programs [43,44].

One interesting result was that "access to the transit stop" was negatively associated with outdoor playtime among children living in rural regions. In Japan, children in rural schools utilize transportation, such as automobiles, when commuting to school more frequently than their urban counterparts [45], and the rate of ownership of transportation vehicles, such as cars and motorcycles, is associated with children's outdoor play. Particularly, as going to a large park in a sports facility in an automobile is essential for safe outdoor play in rural regions, the perception and social support of parents are probably important antecedents of children's outdoor play [46]. From a different perspective, one British study reported that the PA level among 7-year-old children decreases with the increasing number of cars owned by their family [47]. Hence, automobiles should be used selectively in order to increase outdoor playtime, such as walking to kindergarten and traveling on foot when going to stations or shopping. One longitudinal study reported that mothers' PA and screen time behaviors have an important impact on their children's PA and screen time in the first five years of life [48]. Hence, parents' active involvement in PA and simple parent-and-children exercises (Oyako exercises) should be recommended in early childhood [49].

The next key finding was that screen time was significantly associated with "mother's screen time", "TV in the room", and "esthetic qualities" in both urban and rural regions. Our result that the screen time of mothers, including the time spent watching TV and using a smartphone, affected the screen time of children was consistent with previous findings. Furthermore, one study reported that children's TV-watching time increases with an increase in the TV-watching hours of parents, and when parents use other electronic devices, children also frequently use the same electronic device, with the mother's influence being greater than the father's influence [50]. Reports suggest that parents' influence on children's screen time is lost between the ages of 6 and 8 years [51] and that mothers play a crucial role in establishing their child's screen time habits (e.g., limiting screen time or checking the content of the program) [52], suggesting that mothers' attention and guidance are pivotal in the preschool period. With regard to the effect of having a "TV in the room", a review on preschool-age children [53] showed mixed results, where it was both positively associated $[54,55]$ and negatively associated [56] with screen time. As previous studies have generally not reported regional differences, our results, showing a significant association in both urban and rural regions, are highly noteworthy. Furthermore, it has been reported that children who share a room with their sibling for financial reasons, and who have a TV in their room, spend $4.8 \mathrm{~h}$ more time watching TV/videos, regardless of the region [57]. Parents are less likely to impose restrictions regarding screen time and media exposure when the TV is in the child's room instead of in the family space, such as the living room, and these parents are less likely to be involved in children's PA, such as outdoor play. On the basis of our results, encouraging parents to not place the TV and other electronic devices in children's rooms would allow them to more effectively control their children's use of electronic devices and reduce their time spent watching TV, or playing games until late at night. Although imposing restrictions or setting rules for children is important, 
parents (especially mothers) should also reduce their own screen time, enjoy screen time together with their children, and monitor the media content to ensure that children are watching age-appropriate and educational content.

In addition to the physical home environment and sociocultural home environment, screen time was also associated with "esthetic qualities". Although none of the past studies have directly examined this association, considering that access to parks and recreational facilities is consistently correlated with children's PA [58], and that neighbors' perceived esthetics are associated with increased PA [59], children seem to watch TV for fewer hours when there are other attractive things around them. One regional difference observed in our study was that screen time was associated with the "crime rates during the night" and "traffic" items of the "neighborhood environment" domain only in the urban region. A previous study also reported a positive correlation between children's TV-watching hours and crime rates [60], suggesting that the perceived safety risk, owing to a high crime rate, would increase TV watching by strongly inhibiting outdoor playtime. The result pertaining to traffic was consistent with the finding of a previous Western study [60], and a study on adolescents [61]. In contrast to previous studies, however, we observed that the association with traffic was also evident in the urban region, and we can speculate that urban regions would have greater traffic than rural regions owing to high road connectivity. Factors, such as excessive noise, fast car speeds, and lack of school zones may reduce outdoor activity among preschool-age children; thus, children spend their leisure time watching TV or playing games at home. On the basis of these results, further research is needed on neighborhood environments, social factors, and family factors in order to prevent excessive screen time among children.

A few limitations should be considered when interpreting our results. First, as this is a cross-sectional study, causality cannot be established between outdoor playtime/screen time and environmental factors by region. Therefore, a longitudinal or intervention study should be conducted to clarify this relationship. Second, our study was conducted among preschool-age children in a few regions of Japan; hence, our findings have limited generalizability to the entire preschool-age population in Japan. Third, as with other studies conducted on preschool-age children, we used a questionnaire survey in which children's parents or other families provided responses based on their observations of the children's behaviors. Despite these limitations, our findings bolster evidence of the associations of outdoor playtime and screen time with various environmental factors in preschool-age children and has significant implications for developing effective interventions to promote outdoor play and reduce screen time.

\section{Conclusions}

In summary, our study further bolsters evidence suggesting that outdoor playtime and screen time are strongly associated with various environmental factors in Japanese preschool-age children. The associations of outdoor playtime with the mother's sedentary time, and the number of siblings and friends, were consistent between the urban and rural regions, while there were significant associations with the neighborhood environment among urban participants, and with the physical home environment and sociocultural home environment among rural participants. Furthermore, the association of screen time with the mother's screen time, TV in the room, and esthetic qualities was consistent between the urban and rural regions, while screen time was associated with crime rates during the night and traffic in the urban region. In the future, urban environmental plans should target establishing a crime-free environment, esthetic landscapes, and traffic safety such that parents can feel safe having their children spend more time outdoors. Our study was conducted on a rarely studied preschool-age population in Japan; hence, our findings have significant implications for developing effective interventions to promote outdoor play and reduce screen time and can contribute to promoting the health of preschool-age children. 
Author Contributions: Q.W. and H.K. conceptualized and drafted the initial manuscript, and coordinated data collection; J.M., S.K., H.S. and K.H. conceptualized and drafted the initial manuscript, and carried out the statistical analyses; J.M. and H.K. conceptualized and drafted the initial manuscript, carried out the statistical analyses, and supervised data collection. Q.W., J.M., K.H., S.K. and H.K. contributed in an equal way to the conception and drafting of the paper. All authors have read and agreed to the published version of the manuscript.

Funding: Liaoning Province Scientific Research Funding Project no. wjc202027. This work was supported by JSPS KAKENHI, Grant Number JP 21K11555. This work was supported by the international joint research project at Sendai University (grant numbers: 2018-0027).

Institutional Review Board Statement: The study was conducted according to the guidelines of the Declaration of Helsinki and approved by the Institutional Review Board of the Sendai University Ethics Committee of the Faculty of Sports Science (IRB Number: SU29-22).

Informed Consent Statement: Informed consent was obtained from all subjects involved in the study.

Data Availability Statement: Data is contained within the article.

Conflicts of Interest: The authors declare no conflict of interest. The funders had no role in the study design; in the collection, analyses, or interpretation of data; in the writing of the manuscript; or in the decision to publish the results.

\section{References}

1. Hills, A.P.; King, N.A.; Armstrong, T.P. The Contribution of Physical Activity and Sedentary Behaviours to the Growth and Development of Children and Adolescents. Sports Med. 2007, 37, 533-545. [CrossRef]

2. World Health Organization (WHO). Guidelines on Physical Activity, Sedentary Behaviour and Sleep for Children under 5 Years of Age; WHO: Geneva, Switzerland, 2019.

3. Pedišić, Ž.; Dumuid, D.; Olds, T.S. Integrating sleep, sedentary behaviour, and physical activity research in the emerging field of time-use epidemiology: Definitions, concepts, statistical methods, theoretical framework, and future directions. Kinesiology 2017, 49, 252-269.

4. Baranowski, T.; Thompson, W.O.; DuRant, R.H.; Baranowski, J.; Puhl, J. Observations on physical activity in physical locations: Age, gender, ethnicity, and month effects. Res. Q. Exerc. Sport 1993, 64, 127-133. [CrossRef] [PubMed]

5. Benham-Deal, T. Preschool Children's Accumulated and Sustained Physical Activity. Percept. Mot. Ski. 2005, 100, 443-450. [CrossRef]

6. Burdette, H.L.; Whitaker, R.C. Resurrecting free play in young children: Looking beyond fitness and fatness to attention, affiliation, and affect. Arch. Pediatr. Adolesc. Med. 2005, 159, 46-50. [CrossRef]

7. Zask, A.; van Beurden, E.; Barnett, L.; Brooks, L.O.; Dietrich, U.C. Active school playgrounds-myth or reality? Results of the "move it groove it" project. Prev. Med. 2001, 33, 402-408. [CrossRef]

8. Veitch, J.; Bagley, S.; Ball, K.; Salmon, J. Where do children usually play? A qualitative study of parents' perceptions of influences on children's active free-play. Health Place 2006, 12, 383-393. [CrossRef]

9. Sallis, J.F.; Prochaska, J.J.; Taylor, W.C. A review of correlates of physical activity of children and adolescents. Med. Sci. Sports Exerc. 2000, 32, 963-975. [CrossRef]

10. Brussoni, M.; Gibbons, R.; Gray, C.; Ishikawa, T.; Sandseter, E.B.H.; Bienenstock, A.; Chabot, G.; Fuselli, P.; Herrington, S.; Janssen, I.; et al. What is the Relationship between Risky Outdoor Play and Health in Children? A Systematic Review. Int. J. Environ. Res. Public Health 2015, 12, 6423-6454. [CrossRef] [PubMed]

11. Bento, G.; Dias, G. The importance of outdoor play for young children's healthy development. Porto Biomed. J. 2017, 2, 157-160. [CrossRef] [PubMed]

12. Milteer, R.M.; Ginsburg, K.R.; Mulligan, D.A.; Ameenuddin, N.; Brown, A.; Christakis, D.A.; Cross, C.; Falik, H.L.; Hill, D.L.; Hogan, M.J.; et al. The Importance of Play in Promoting Healthy Child Development and Maintaining Strong Parent-Child Bond: Focus on Children in Poverty. Pediatrics 2011, 129, e204-e213. [CrossRef] [PubMed]

13. Gladwell, V.F.; Brown, D.K.; Wood, C.; Sandercock, G.R.; Barton, J.L. The great outdoors: How a green exercise environment can benefit all. Extrem. Physiol. Med. 2013, 2, 3. [CrossRef] [PubMed]

14. Gray, P. The decline of play and the rise of psychopathology in children and adolescents. Am. J. Play. $2011,3,443-463$.

15. Cleland, V.; Timperio, A.; Salmon, J.; Hume, C.; Baur, L.A.; Crawford, D. Predictors of time spent outdoors among children: 5-year longitudinal findings. J. Epidemiol. Community Health 2009, 64, 400-406. [CrossRef]

16. Canadian Parks and Recreation Association. Reporting on the Pan Canadian Survey Re: Children and Nature; Canadian Parks and Recreation Association: Ottawa, Canada, 2010; Available online: https://s3.amazonaws.com/s3.arpaonline.ca/Children-NatureSurvey-Report.pdf (accessed on 13 July 2021).

17. Karsten, L. It all used to be better? Different generations on continuity and change in urban children's daily use of space. Child. Geogr. 2005, 3, 275-290. [CrossRef] 
18. Sedentary Behaviour Research Network. Standardized use of the terms "sedentary" and "sedentary behaviours". Appl. Physiol. Nutr. Metab. 2012, 37, 540-542. [CrossRef]

19. Jones, R.A.; Hinkley, T.; Okely, A.D.; Salmon, J. Tracking physical activity and sedentary behavior in childhood: A systematic review. Am. J. Prev. Med. 2013, 44, 651-658. [CrossRef]

20. Hnatiuk, J.A.; Salmon, J.; Hinkley, T.; Okely, A.D.; Trost, S. A Review of Preschool Children's Physical Activity and Sedentary Time Using Objective Measures. Am. J. Prev. Med. 2014, 47, 487-497. [CrossRef]

21. Carson, V.; Kuzik, N.; Hunter, S.; Wiebe, S.A.; Spence, J.C.; Friedman, A.; Tremblay, M.S.; Slater, L.G.; Hinkley, T. Systematic review of sedentary behavior and cognitive development in early childhood. Prev. Med. 2015, 78, 115-122. [CrossRef]

22. Biswas, A.; Oh, P.I.; Faulkner, G.E.; Bajaj, R.R.; Silver, M.A.; Mitchell, M.S.; Alter, D.A. Sedentary time and its association with risk for disease incidence, mortality, and hospitalization in adults: A systematic review and meta-analysis. Ann. Intern. Med. 2015, 162, 123-132. [CrossRef] [PubMed]

23. Biddle, S.J.; Pearson, N.; Ross, G.M.; Braithwaite, R. Tracking of sedentary behaviours of young people: A systematic review. Prev. Med. 2010, 51, 345-351. [CrossRef] [PubMed]

24. Kim, H.; Ma, J.; Harada, K.; Lee, S.; Gu, Y. Associations between Adherence to Combinations of 24-h Movement Guidelines and Overweight and Obesity in Japanese Preschool Children. Int. J. Environ. Res. Public Health 2020, 17, 9320. [CrossRef]

25. Sallis, J.F.; Cervero, R.B.; Ascher, W.; Henderson, K.A.; Kraft, M.K.; Kerr, J. An ecological approach to creating active living communities. Annu. Rev. Public Health 2006, 27, 297-322. [CrossRef]

26. Joens-Matre, R.R.; Welk, G.J.; Calabro, M.A.; Russell, D.W.; Nicklay, E.; Hensley, L.D. Rural-urban differences in physical activity, physical fitness, and overweight prevalence of children. J. Rural Health 2008, 24, 49-54. [CrossRef] [PubMed]

27. Loucaides, C.A.; Chedzoy, S.M.; Bennett, N. Differences in physical activity levels between urban and rural school children in Cyprus. Health Educ. Res. 2004, 19, 138-147. [CrossRef]

28. Davis, A.; Boles, R.; James, R.L.; Sullivan, D.K.; Donnelly, J.E.; Swirczynski, D.L.; Goetz, J. Health behaviors and weight status among urban and rural children. Rural Remote Health 2008, 8, 810. [CrossRef] [PubMed]

29. Bathrellou, E.; Lazarou, C.; Panagiotakos, D.B.; Sidossis, L.S. Physical Activity Patterns and Sedentary Behaviors of Children from Urban and Rural Areas of Cyprus. Cent. Eur. J. Public Health 2007, 15, 66-70. [CrossRef]

30. Wang, Q.; Ma, J.; Maehashi, A.; Kim, H. The Associations between Outdoor Playtime, Screen-Viewing Time, and Environmental Factors in Chinese Young Children: The "Eat, Be Active and Sleep Well" Study. Int. J. Environ. Res. Public Health 2020, $17,4867$. [CrossRef]

31. Sallis, J.F.; Kerr, J.; Carlson, J.A.; Norman, G.; Saelens, B.; Durant, N.; Ainsworth, B.E. Evaluating a Brief Self-Report Measure of Neighborhood Environments for Physical Activity Research and Surveillance: Physical Activity Neighborhood Environment Scale (PANES). J. Phys. Act. Health 2010, 7, 533-540. [CrossRef] [PubMed]

32. Inoue, S.; Murase, N.; Shimomitsu, T.; Ohya, Y.; Odagiri, Y.; Takamiya, T.; Ishii, K.; Katsumura, T.; Sallis, J.F. Association of physical activity and neighborhood environment among Japanese adults. Prev. Med. 2009, 48, 321-325. [CrossRef]

33. World Health Organization. Global Physical Activity Surveillance. Available online: https://www.who.int/teams/ noncommunicable-diseases/surveillance/systems-tools/physical-activity-surveillance. (accessed on 13 July 2021).

34. Inoue, S.; Nakata, Y.; Ohkawara, K.; Oka, K.; Oguma, Y.; Takada, K.; Tanaka, S.; Tanaka, C. Development of Japanese version of the GPAQ. Jpn. J. Phys. Fit. Sports Med. 2016, 65, 155. (In Japanese)

35. Burdette, H.L.; Whitaker, R.C.; Daniels, S.R. Parental Report of Outdoor Playtime as a Measure of Physical Activity in Preschoolaged Children. Arch. Pediatr. Adolesc. Med. 2004, 158, 353-357. [CrossRef] [PubMed]

36. Nelson, N.M.; Wright, A.; Lowry, R.G.; Mutrie, N. Where is the theoretical basis for understanding and measuring the environment for physical activity? Environ. Health Insights 2008, 2, 111-116. [CrossRef]

37. Garriguet, D.; Colley, R.; Bushnik, T. Parent-Child Association in Physical Activity and Sedentary Behavior; Statistics Canada: Ottawa, ON, Canada, 2017; Volume 28.

38. Jago, R.; Solomon-Moore, E.; Macdonald-Wallis, C.; Sebire, S.J.; Thompson, J.L.; Lawlor, D.A. Change in children's physical activity and sedentary time between Year 1 and Year 4 of primary school in the B.-PROACT1V cohort. Int. J. Behav. Nutr. Phys. Act. 2017, 14, 33. [CrossRef]

39. Aggio, D.; Gardner, B.; Roberts, J.; Johnstone, J.; Stubbs, B.; Williams, G.; Sánchez, G.F.L.; Smith, L. Correlates of children's independent outdoor play: Cross-sectional analyses from the Millennium Cohort Study. Prev. Med. Rep. 2017, 8, 10-14. [CrossRef] [PubMed]

40. Sallis, J.F.; Glanz, K. The Role of Built Environments in Physical Activity, Eating, and Obesity in Childhood. Future Child. 2006, 16, 89-108. [CrossRef] [PubMed]

41. Huang, S.; Hung, W.; Sharpe, P.A.; Wai, J.P. Neighborhood environment and physical activity among urban and rural schoolchildren in Taiwan. Health Place 2010, 16, 470-476.

42. Kristjansdottir, G.; Vilhjalmsson, R. Sociodemographic differences in patterns of sedentary and physically active behaviour in older children and adolescents. Acta Paediatr. 2001, 90, 429-435. [CrossRef]

43. Krizek, K.J.; Birnbaum, A.S.; Levinson, D.M. A schematic for focusing on youth in investigations of community design and physical activity. Am. J. Health Promot. 2004, 19, 33-38. [CrossRef]

44. Saelens, B.E.; Sallis, J.F.; Frank, L.D. Environmental correlates of walking and cycling: Findings from the transportation, urban design, and planning literatures. Ann. Behav. Med. 2003, 25, 80-91. [CrossRef] 
45. Itoi, A.; Yamada, Y.; Watanabe, Y.; Kimura, M. Physical activity, energy intake, and obesity prevalence among urban and rural schoolchildren aged 11-12 years in Japan. Appl. Physiol. Nutr. Metab. 2012, 37, 1189-1199. [CrossRef] [PubMed]

46. Beets, M.W.; Vogel, R.; Chapman, S.; Pitetti, K.H.; Cardinal, B.J. Parent's social support for children's outdoor physical activity: Do weekdays and weekends matter? Sex Roles 2007, 56, 125-131. [CrossRef]

47. Pouliou, T.; Sera, F.; Griffiths, L.; Joshi, H.; Geraci, M.; Cortina-Borja, M.; Law, C. Environmental influences on children's physical activity. J. Epidemiol. Community Health 2014, 69, 77-85. [CrossRef] [PubMed]

48. Wiseman, N.; Harris, N.; Downes, M. Preschool children's preferences for sedentary activity relates to parent's restrictive rules around active outdoor play. BMC Public Health 2019, 19, 946. [CrossRef]

49. Maebashi, A. A happy future for children in Japan, starting today. J. Phys. Educ. Young Child. Asia 2016, 5, 3-6. (In Japanese)

50. Hu, B.Y.; Johnson, G.K.; Wu, H. Screen time relationship of Chinese parents and their children. Child. Youth Serv. Rev. 2018, 94, 659-669. [CrossRef]

51. Lauricella, A.; Wartella, E.; Rideout, V.J. Young children's screen time: The complex role of parent and child factors. J. Appl. Dev. Psychol. 2015, 36, 11-17. [CrossRef]

52. Thompson, A.L.; Adair, L.S.; Bentley, M.E. Maternal Characteristics and Perception of Temperament Associated with Infant TV Exposure. Pediatrics 2013, 131, e390-e397. [CrossRef] [PubMed]

53. Kim, H.; Akira, M.; Ma, J. Factors impacting levels of physical activity and sedentary behavior among young children: A literature review. IJASS 2017, 29, 1-12. [CrossRef]

54. Vandewater, E.A.; Rideout, V.J.; Wartella, E.A.; Huang, X.; Lee, J.H.; Shim, M.-S. Digital Childhood: Electronic Media and Technology Use among Infants, Toddlers, and Preschoolers. Pediatrics 2007, 119, e1006-e1015. [CrossRef]

55. Bleakley, A.; Jordan, A.B.; Hennessy, M. The Relationship between Parents' and Children's Television Viewing. Pediatrics 2013, 132, e364-e371. [CrossRef] [PubMed]

56. Yalçin, S.S.; Tugrul, B.; Naçar, N.; Tuncer, M.; Yurdakok, K. Factors that affect television viewing time in preschool and primary schoolchildren. Pediatr. Int. 2002, 44, 622-627. [CrossRef]

57. Dennison, B.A.; Erb, T.A.; Jenkins, P.L. Television viewing and television in bedroom associated with overweight risk among low-income preschool children. Pediatrics 2002, 109, 1028-1035. [CrossRef] [PubMed]

58. Davison, K.K.; Lawson, C.T. Do attributes in the physical environment influence children's physical activity? A review of the literature. Int. J. Behav. Nutr. Phys. Act. 2006, 3, 19. [CrossRef] [PubMed]

59. Mota, J.; Almeida, M.; Santos, M.P.; Ribeiro, J. Perceived Neighborhood Environments and physical activity in adolescents. Prev. Med. 2005, 41, 834-836. [CrossRef]

60. Timperio, A.; Salmon, J.; Ball, K.; te Velde, S.J.; Brug, J.; Crawford, D. Neighborhood characteristics and TV viewing in youth: Nothing to do but watch TV? J. Sci. Med. Sport 2012, 15, 122-128. [CrossRef]

61. Carson, V.; Janssen, I. Neighborhood disorder and screen time among 10-16 years old Canadian youth: A cross-sectional study. Int. J. Behav. Nutr. Phys. Act. 2012, 9, 66. [CrossRef] 